\title{
Lusioersily
}

\section{Role of Serine/Threonine Kinase 11 (STK11) or liver kinase B1 (LKB1) Gene in Peutz- Jeghers Syndrome}

Altamish, M., Dahiya, R., Singh, A. K., Mishra, A., Aljabali, A. A. A., Satija, S., Mehta, M., Dureja, H., Prasher, P., Negi, P., Kapoor, D. N., Goyal, R., Tambuwala, M. M., Chellappan, D. K., Dua, K., \& Gupta, G. (2020). Role of Serine/Threonine Kinase 11 (STK11) or liver kinase B1 (LKB1) Gene in Peutz-Jeghers Syndrome. Critical Reviews in Eukaryotic Gene Expression, 30(3), 245-252.

https://doi.org/10.1615/CritRevEukaryotGeneExpr.2020033451

Link to publication record in Ulster University Research Portal

\section{Published in:}

Critical Reviews in Eukaryotic Gene Expression

\section{Publication Status:}

Published online: 12/05/2020

DOI:

10.1615/CritRevEukaryotGeneExpr.2020033451

\section{Document Version}

Author Accepted version

\section{General rights}

Copyright for the publications made accessible via Ulster University's Research Portal is retained by the author(s) and / or other copyright owners and it is a condition of accessing these publications that users recognise and abide by the legal requirements associated with these rights.

\section{Take down policy}

The Research Portal is Ulster University's institutional repository that provides access to Ulster's research outputs. Every effort has been made to ensure that content in the Research Portal does not infringe any person's rights, or applicable UK laws. If you discover content in the Research Portal that you believe breaches copyright or violates any law, please contact pure-support@ulster.ac.uk. 


\section{Role of Serine/Threonine Kinase 11 (STK11) or liver kinase B1 (LKB1) Gene in Peutz- Jeghers Syndrome}

Mohammad Altamish ${ }^{1}$, Rajiv Dahiya ${ }^{2}$, Avinash Kumar Singh ${ }^{1}$, Anurag Mishra ${ }^{3}$, Alaa A. A. Aljabali ${ }^{4}$, Saurabh Satija ${ }^{5}$, Meenu Mehta ${ }^{5}$,Harish Dureja ${ }^{6}$, Parteek Prasher ${ }^{7}$, Poonam Negi ${ }^{8}$, Deepak N. Kapoor ${ }^{8}$, Rohit Goyal ${ }^{8}$, Murtaza M Tambuwala ${ }^{9}$, Dinesh K. Chellappan ${ }^{10}$, Kamal Dua $^{11,12,13}$, Gaurav Gupta ${ }^{14}$

1. Department of Pharmacology, School of Pharmaceutical Education and Research, Jamia Hamdard. New Delhi - 110062, India

2. Laboratory of Peptide Research and Development, School of Pharmacy, Faculty of Medical Sciences, The University of the West Indies, St. Augustine, Trinidad \& Tobago, West Indies

3. School of Pharmacy, Suresh Gyan Vihar University, Mahal Road, Jagatpura, Jaipur, India

4. Faculty of Pharmacy, Department of Pharmaceutical Sciences, Yarmouk University, Irbid 21163, Jordan

5. School of Pharmaceutical Sciences, Lovely Professional University, Phagwara, Punjab 144411, India

6. Department of Pharmaceutical Sciences, Maharishi Dayanand University, Rohtak, Haryana 124001, India.

7. Department of Chemistry, University of Petroleum \& Energy Studies, Dehradun 248007, India

8. School of Pharmaceutical Sciences, Shoolini University of Biotechnology and Management Sciences, Solan, 173229, India 
9. School of Pharmacy and Pharmaceutical Sciences, Ulster University, Coleraine, County, Londonderry, BT52 1SA, Northern Ireland, United Kingdom

10. Department of Life Sciences, School of Pharmacy, International Medical University, Bukit Jalil, Kuala Lumpur, Malaysia 57000

11. Centre for Inflammation, Centenary Institute, Sydney, NSW 2050, Australia.

12. Priority Research Centre for Healthy Lungs, Hunter Medical Research Institute (HMRI) \& School of Biomedical Sciences and Pharmacy, The University of Newcastle (UoN), Callaghan, NSW 2308, Australia.

13. Discipline of Pharmacy, Graduate School of Health, University of Technology Sydney (UTS), Ultimo, NSW 2007, Australia.

Corresponding Author: Gaurav Gupta, School of Pharmacy, Suresh Gyan Vihar University, Mahal Road, Jagatpura, Jaipur, India.

Email id: gauravpharma25@gmail.com

\begin{abstract}
Peutz-Jeghers syndrome (PJS) is a well-described inherited syndrome, characterized by the development of gastrointestinal polyps, and characteristic mucocutaneous freckling. PJS, an autosomal prevailing disease due to genetic mutation on chromosome $19 \mathrm{p}$, manifested by restricted mucocutaneous melanosis in association with gastrointestinal (GI) polyposis. The gene for PJS has recently been shown to be a serine/threonine kinase, known as LKB1 or STK11, which maps to chromosome subband 19p13.3. This gene has a putative coding region of 1302
\end{abstract}


$\mathrm{bp}$, divided into nine exons, and acts as a tumour suppressor in the hamartomatous polyps of PJS patients and in the other neoplasms which develop in PJS patients. It is probable that these neoplasms develop from hamartomas, but remains possible that the LKB1 or STK11 locus plays a role in a different genetic pathway of tumour growth in the cancers of PJS patients. This article has focused on role of LKB1 or STK11 gene expression in PJS and related cancers.

Keywords: Peutz-Jeghers syndrome; LKB1; STK11; gastrointestinal polyps; gene expression

\section{Introduction}

Peutz-Jeghers syndrome (PJS) is characterized by a specific type of hamartomatous polyp of the gastrointestinal tract, and by freckling of the lips, buccal mucosa, and other sites. PJS often presents in the first decade of life with pigmentation (usually in a familial context) or with complications of small bowel polyps, such as obstruction or intussusception. Older PJS patients have an increased risk of neoplasia of multiple sites, predominantly the colon, breast, stomach, ovary, uterus, and pancreas. This risk may approach a 20 -fold increase over the general population if all organs are considered, although the increased risk for any particular site is necessarily more modest. About three quarters of PJS cases occur in families, with the remainder resulting from new mutations or low penetrance variants ${ }^{1,2}$.

The gene for PJS has recently been shown to be a serine/threonine kinase, known as LKB1 or STK11, which maps to chromosome subband 19p13.3. This gene has a putative coding region of $1302 \mathrm{bp}$, divided into nine exons, and acts as a tumour suppressor in the hamartomatous polyps of PJS patients and in the other neoplasms which develop in PJS patients. It is probable that these 
neoplasms develop from hamartomas, but remains possible that the LKB1 locus plays a role in a different genetic pathway of tumour growth in the cancers of PJS patients ${ }^{3,4}$.

Previous studies have found germline LKB1 mutations in 50-75\% of Peutz-Jeghers patients using genomic DNA or cDNA sequencing as a primary screen. Most of these mutations are frameshifts or nonsense changes and thus result in a truncated protein. In frame deletions or missense mutations occur less frequently, generally at conserved amino acids in the kinase core (codons 50-337). Although data are currently insufficient for a formal analysis, the germline mutations of Peutz-Jeghers patients appear to occur throughout the gene, but with a possible bias towards exons 1 and 6. Most studies have reported few somatic LKB1 mutations in sporadic cancers, despite screening tumours from most of the sites (colon, breast, testis, ovary, and pancreas) at which PJS patients have an excess of cancers. One study has, however, found a high frequency of missense LKB1 mutations in left sided sporadic colon cancers. In addition, one somatic mutation with convincing pathogenic effects has been reported in a sporadic testicular cancer and two mutations have been found in malignant melanoma. There is some evidence of a second, minor PJS locus not on 19p13.3 and, although its existence remains unproven, it may explain why mutation screening does not detect a higher frequency of LKB1 mutations in PJS patients ${ }^{5-8}$.

\section{Genetic defects in Peutz-Jeghers syndrome}

Mucocutaneous melanosis associated with PJS is autosomal disorder and in 1997 it was discovered that expression of it related to chromosome 19p13.3. However, further research findings by two-research groups revealed the involvement of LKB1 (liver kinase B1) gene mutation (also recognised as STK11 [serine/threonine kinase 11] gene) on expression of mucocutaneous melanosis. A $30 \%-70 \%$ of PJS sporadic cases associated with STK11/LKB1 
gene mutation, however, the rate of spontaneous mutation in mucocutaneous melanosis is under investigation ${ }^{9,10}$. The main setback in identification of STK11/LKB1 gene in mucocutaneous melanosis patients is genetic mosaicism, lack of effective molecular techniques PJS loci, etc.. Later some studies on PJS revealed the link of loci on chromosome 16q and19q for expression of mucocutaneous melanosis. These mutations on PJS leads to null alleles by nonsense insertion, deletion and rearrangement ${ }^{11,12}$.

Additionally, Hemminki and team revealed the involvement of STK11 gene mutation in almost $90 \%$ of PJS patients by DNA and mRNA direct sequencing method. On the other hand, germline mutations were simultaneously investigated by multiplex ligation dependent probe amplification and direct sequencing method, where the results detects 80 to $94 \%$ of germline mutations in PJS patients. PJS polyps showed loss of heterozygosity at 19p13.3. SKT11 also act as a tumor suppressor gene, which is almost $23 \mathrm{~kb}$ in length along with 433 amino acid and nine-axon. Further investigation on function and activity of SKT11 is still ongoing. The expression of serine-threonine kinase is wide in fetal tissue and adult. In short, G1 cell-cycle arrest, p53 mediated apoptosis and WAF1 signalling is mediated by STK11 and plays important role in regulation of Wnt signalling pathway and cell polarity. Moreover, it is also take part in cell homeostasis and metabolism, and also act as a upstream regulator of adenosine monophosphate activated protein kinase and control tuberous sclerosis complex pathway along with negative regulation of mammalian target of rapamycin pathway ${ }^{13-15}$. Mammalian target of rapamycin pathway is final common pathway and also can be downregulated by other hamartomatous polyposis syndromes triggered by SMAD4, germline PTEN and BMPR1A mutations. 
Abundance of COX-2 also noticed in case of cancer and PJS polyps, can target for modulation of PJS. Additionally, role of MYH11 gene mutation in 25 STK11mutation negative patients having PJS phenotype were examined ${ }^{16-18}$. One patient was found with MYH11 mutation; however, this mutation was modest relevance. Until now, no confirmed gene was found for mucocutaneous melanosis cases without detectable STK1 1 mutation ${ }^{19,20}$.

\section{Correlation between genotype and phenotype}

Various researchers around the world investigated correlation between phenotype and genotype in PJS. Amos et al found out that persons with other mutation in STK11 have early onset of PJS symptoms compared to person with missense mutations. On the other hand, Schumacher et al proposed that in-frame mutation in ATP binding, catalysis (IeVIA) and encoding protein domain were hardly related to cancer; however, missense mutation in the part of encoding protein domain gene and $\mathrm{C}$ terminus were more likely associated with malignancies. They also suggested that truncating mutations predominantly found in breast carcinoma. Moreover, Mehenni et al proposed mutations in exon 6 of the STK11 associated with the higher risk of cancer following investigating on 49 PJS family with mutations ${ }^{21,22}$. Although, it is difficult to draw final conclusion from these studies with small numbers of patients. Majority of these studies was carried out in western European populations, whereas, in one of the studies in American PJS patients illustrated the involvement of exon 6 (c.811_813delAG) and exon 2 (c.350_351insT) mutation of STK11gene in PJS ${ }^{17,23,24}$. STK11 mutation were analysed in 240 PJS patients and families and no difference was observed neither in truncating and missense mutations in individual, nor in sporadic and familial cases. However, mutation in exon 3 of the gene was found to cause higher risk of cancer in individual. Continuation of this study, Hearle et 
al analysed 419 patient in which 297 patients were document for mutations and concluded that site and type of mutation did not affect the cancer risk in individual. In summary, no significant differences was observed in PJS patients without mutation and patients with STK11 mutation. Moreover, no correlation has been observed in genotype and phenotype of the patients ${ }^{25-27}$.

\section{Clinical Characteristics of PJS}

A disease resembling PJS was described by Peutz in 1921 and by Jeghers et al in 1949. The pathology of PJS is considered to be hamartomatous, since PJS polyps are not cancerous and their histology is similar to the normal mucosal structure. A more accurate description of the lesions is hyperplasia of the lacunar epithelium. However, the morphology differs from that of a general hyperplastic polyp. The gland opening is dilated toward the outer side due to the hyperplastic mucoepithelium and muscular fibers overgrow in a dendritic pattern along the epithelium. These changes are preceded by epithelial hyperplasia. Adjacent lamina muscularis mucosae are believed to bend and fuse to give the characteristic appearance and small lesions undergo hyperplastic changes ${ }^{28,29}$.

Clinically, PJS is characterized by the development of abdominal symptoms, including pain, ileus and gastrointestinal hemorrhage, which occur with an increase in the number and size of the gastrointestinal polyps. The incidence of PJS is secondary to that of familial adenomatous polyposis among the types of hereditary gastrointestinal polyposis. Malignant and benign tumor complications may occur in PJS, with studies indicating that malignant tumors develop in approximately half of patients by the age of 57 years ${ }^{30-32}$. The incidence of digestive organ malignant tumors is highest in the colorectum, followed by the stomach, small intestine, duodenum and pancreas. In regions other than the digestive organs, the incidence is reported to 
be highest in the uterine cervix, followed by the lung and ovary in female PJS patient. Associations with ovarian SCTAT and uterine cervical LEGH and MDA have been highlighted in the field of gynecology, and an association with endometrial cancer has recently gained interest based on case reports and genetic studies ${ }^{33-36}$.

\section{Associated cancer risk with PJS}

PJS association with cancer and involvement of PJS polyp in cancer development is still controversial. Hypothesis of hamartoma adenoma carcinoma pathway was supported by presence of adenomatous foci in polyp of PJS and also describe possible rising of cancer from polyp. Some researchers proposed that PJS polyp is not having malignant potency and thus, cancer transformation of polyp is rarely ensued ${ }^{37-39}$. Moreover, PJS polyp found to be polyclonal and actually a form of abnormal mucosal prolapse arises due mutation in STK11 gene leads to change in cellular polarity, it is not a type of true hamartoma. As there is no involvement of PJS polyp in cancer, so background of cancer development may have associated with mucosal instability, through neoplastic pathways ${ }^{40-42}$. On the basis of several molecular genetics and epidemiological studies, it was suggested the PJS patients have higher risk of many cancer. It was evident from the literature that multiple studies have been performed on individual groups, however, it is difficult to conclude the cancer risk association with PJS due to publication bias and ascertainment of these studies ${ }^{43-45}$. In this regard, meta-analysis was performed by Giardiello et al on six studies with total 210 patients. Similarly, as stated above 419 patients with PJS was assessed by Hearle and team to generate comprehensive data for cancer risk association with PJS. As per findings, out of 419, 297 patients were documented to have STK11 mutations and $23 \%$ of them developed cancer. From these studies, it was proposed that breast cancer and

luminal GI cancers is most common cancer associated with it, followed by pancreatic cancer ${ }^{46-}$ 
${ }^{48}$. Hearle and team reported the higher risk of cancer after the age of 50. Recently, Mehenni et al investigated 76 males and 73 females with STK11 mutation and on contrary to the above study report, they reported only one breast cancer. Although the reason of this discrepancy in observation in these studies are still in question. Else the luminal GI cancer predominance and more risk after age of 50 was established by these study ${ }^{49-51}$. Alternately, Young et al investigated occurrence of rare sex cord tumour in PJS. They found that out of 74 patients with sex cord ovarian tumors with annular tubules, 27 were documented with PJS and all were benign, calcified and multifocal. Four affected patients had adenoma malignum and twelve have hyper-oestrogen syndrome ${ }^{52-54}$. Additionally, Dozois and team reviewed 115 female PJS cases from literature and found 16 cases of ovarian tumors at the age from 4.5 to 60 years. Moreover, five cystadenomas, five granulosa cell tumours, four non-neoplastic cysts, one dysgerminoma and one Brenner tumor were diagnosed. A case of broncho-alveolar cancer was reported by Von Herbay to show association of cancer with PJS ${ }^{55-57}$. Obtained reports in this field demonstrated several controversial theories relating development of PJS and cancer, however majority of incidences are focusing on hamartoma polyposis in the GI tract, no correlation evidenced on mucocutaneous melanosis with any incidence of cancer. Connecting section of the article will bring available possibilities in the management of these mucocutaneous melanosis in PJS ${ }^{58-60}$.

\section{STK11/LKB1 and PJS}

The gene that is responsible for causing PJS is the tumor suppressor gene, STK11/LKB1, which is located on the short arm of chromosome 19 (19p13.3). The gene is $23 \mathrm{~kb}$ in size and is comprised of nine coding exons and one non-coding exon. The gene encodes a serine threonine kinase containing 433 amino acids. The mRNA is $3.0-3.3 \mathrm{~kb}$ in size and is expressed in almost all human tissues. Germline mutations of STK11/LKB1 are observed in more than half of PJS 
patients. However, the somatic development of PJS in patients with no familial medical history and cases without a mutation in STK11/LKB1 have also been described ${ }^{61-63}$.

In 1997, Hemminki et al identified the responsible gene region in PJS to be near the chromosome 19 short arm marker using a linkage analysis of families with PJS. Amos et al confirmed this finding. The STK11 gene was known to be present on chromosome 19 and Yoon et al subsequently identified a number of mutation types in this gene, including missense, frame shift, nonsense and splicing site mutations, in 10 PJS patients using polymerase chain reactionsingle strand conformation polymorphism ${ }^{57,64,65}$. Germline mutations were present in five of these patients. Tseng et al analyzed STK11 mRNA expression in twin sisters with PJS with the same allele using PCR and revealed that STK11 gene expression was absent in the two subjects. These results suggest that STK11 on chromosome 19 is responsible for PJS and that a mutation or decreased expression of STK11 is the cause of the disease ${ }^{66-68}$.

The protein product of STK11 is involved in cellular energy metabolism, cell proliferation, cell polarity, p53-dependent apoptosis, the regulation of VEGF and Wnt signal transduction. LOH due to a mutation, including a deletion in the normal allele, in addition to the germline STK11 mutation, results in gastrointestinal polyposis and cancerization of other organs, which are common clinical features of PSJ ${ }^{69,70}$.

As noted previously, Yoon et al identified germline mutations in five of 10 PJS patients, which suggests other developmental mechanisms in the remaining five patients, based on STK11 gene mutation-induced development (somatic case) and the association with other genes. Several studies have suggested the presence of a gene that is associated with PJS other than STK11. In an investigation of 21 PJS patients from 13 families, Papp et al identified that $8(62 \%)$ of the 13 cases of PJS had familial medical histories and that the remaining five cases $(38 \%)$ were due 
to de novo mutations. Germline mutations were screened in the 21 patients and 13 pathogenic mutations of STK11 were identified ${ }^{71-73}$. Three of these were frameshift mutations, three were nonsense mutations, two were mutations of the splicing sequence and five were deletions of exons 1-7. This deletion was noted in five of the 13 families, showing a high frequency, and was also shown to affect two genes that were located upstream of the STK1 1 gene, SBNO2 and GPX4, which are considered to modify STK11. This finding suggests that an abnormality in the genes that modify STK11 function may promote the development of PJS, even in the absence of a mutation in STK11 itself ${ }^{74-77}$.

Souza et al initially reported a contiguous genetic syndrome in which a developmental disorder, heart malformation and facial dysplasia appear as phenotypes, in addition to the symptoms of PSJ. This syndrome is caused by a 19p13.3 chromosomal deletion of a region of $\sim 1.1 \mathrm{Mb}$ that includes STK11. Scollon et al also reported a syndrome with a similar gene deletion at a similar site, but the development of a cleft lip and gastrointestinal polyposis differed between the syndromes, suggesting that the phenotypes may vary, despite a common STK11 deletion between the two syndromes ${ }^{78-80}$.

\section{Conclusion}

The frequency and type of SKT11/LKB1 gene inactivation unequivocally attests to its tumorsuppressor role in lung tumorigenesis and demonstrates its significance in cancer development in other circumstances that merely the cancer-prone PJS. In addition to PJS, the use of highly sensitive screenings for mutations and large deletions may reveal that SKT11/LKB1 gene alterations occur in a broad range of tumor types. Finally, the critical involvement of SKT11/LKB1 in energetic control checkpoints highlights the importance of these processes in 
PJS, carcinogenesis and provides novel potential targets for gene screening in tumors and for therapeutic intervention.

\section{References}

1. Iwamuro M, Toyokawa T, Moritou Y, Matsueda K, Hori S, Yoshioka M, Tanaka T, Kawano S, Okada H. [Peutz-Jeghers syndrome and cancer:a retrospective study in 14 Japanese patients with PeutzJeghers syndrome]. Nihon Shokakibyo Gakkai zasshi = The Japanese journal of gastro-enterology. 2019;116(12):1015-21.

2. Jaegle WT, Keyser EA, Messersmith L, Brady RO, Miller C. Extraovarian sex cord tumor with annular tubules discovered arising from a leiomyoma. Gynecologic oncology reports. 2018;26:17-20. 3. Jedrzkiewicz J, Quencer K, Matynia AP, Morrow E, Pletneva M, Barraza G. Peutz-Jeghers Type Polyp of the Appendix with Review of Literature. Case reports in pathology. 2019;2019:7584070.

4. Ji F, Sun C, Rizeq FK, Pu M, Yang H, Dong X, Wang Z, Chang W, Yang Z. PIGMENTED MACULES REMOVAL WITH COSMETIC TREATMENT MAY COVER UP PEUTZ-JEGHERS SYNDROME: A CASE REPORT. Gastroenterology nursing : the official journal of the Society of Gastroenterology Nurses and Associates. 2019;42(6):504-7.

5. Jia Y, Fu H, Li N, Kang Q, Sheng J. [Diagnosis and treatment for 46 cases of Peutz-Jeghers syndrome]. Zhong nan da xue xue bao Yi xue ban = Journal of Central South University Medical sciences. 2018;43(12):1323-7.

6. Jiang L, Jiao YF. [Clinicopathological features of non-neoplastic colorectal polyps]. Zhonghua bing li xue za zhi $=$ Chinese journal of pathology. 2019;48(2):98-101.

7. Jiang YL, Zhao ZY, Li BR, Li J, Jin XW, Yu ED, Xu XD, Ning SB. Early screening the small bowel is key to protect Peutz-Jeghers syndrome patients from surgery: a novel mutation c.243delG in STK11 gene. BMC gastroenterology. 2019;19(1):70.

8. Jiang YL, Zhao ZY, Li BR, Wang H, Yu ED, Ning SB. STK11 gene analysis reveals a significant number of splice mutations in Chinese PJS patients. Cancer genetics. 2019;230:47-57.

9. Jiang YL, Zhao ZY, Li BR, Yang F, Li J, Jin XW, Wang H, Yu ED, Sun SH, Ning SB. The altered activity of P53 signaling pathway by STK11 gene mutations and its cancer phenotype in Peutz-Jeghers syndrome. BMC medical genetics. 2018;19(1):141.

10. Jonsson GG, Atladottir J. [Peutz-Jegher syndrome presenting with intussusception]. Laeknabladid. 2018;104(10):439-41.

11. Kadekar P, Chaouni R, Clark E, Kazanets A, Roy R. Genome-wide surveys reveal polarity and cytoskeletal regulators mediate LKB1-associated germline stem cell quiescence. BMC genomics. 2018;19(1):462.

12. Katabathina VS, Menias CO, Khanna L, Murphy L, Dasyam AK, Lubner MG, Prasad SR. Hereditary Gastrointestinal Cancer Syndromes: Role of Imaging in Screening, Diagnosis, and Management. Radiographics : a review publication of the Radiological Society of North America, Inc. 2019;39(5):1280301.

13. Khanna K, Khanna V, Bhatnagar V. Peutz-Jeghers syndrome: need for early screening. BMJ case reports. 2018;11(1).

14. Kidambi TD, Kohli DR, Samadder NJ, Singh A. Hereditary Polyposis Syndromes. Current treatment options in gastroenterology. 2019;17(4):650-65. 
15. Kim Y, Kim EY, Kim TJ, Lim KT, Lee KH, Chun Y, So KA. A rare case of gastric-type mucinous adenocarcinoma in a woman with Peutz-Jeghers syndrome. Obstetrics \& gynecology science. 2019;62(6):474-7.

16. Tiwari J, Gupta G, de Jesus Andreoli Pinto T, Sharma R, Pabreja K, Matta Y, Arora N, Mishra A, Dua K. Role of microRNAs (miRNAs) in the pathophysiology of diabetes mellitus. Panminerva medica. 2018.

17. Wang B, Gupta G, Singh M, Veerabhadrappa KVS, Mishra A, Chinnaboina GK. Pharmacological evaluation of novel flavone from Morus alba in pentylenetetrazole-induced kindling and oxidative stress. Journal of Environmental Pathology, Toxicology and Oncology. 2018;37(1).

18. Yong DOC, Saker SR, Wadhwa R, Chellappan DK, Madheswaran T, Panneerselvam J, Tambuwala MM, Bakshi HA, Kumar P, Pillay V. Preparation, characterization and in-vitro efficacy of quercetin loaded liquid crystalline nanoparticles for the treatment of asthma. Journal of Drug Delivery Science and Technology. 2019;54:101297.

19. Kirakosyan E, Lokhmatov M. High-Tech Diagnostic Methods and Enteroscopic Treatment of Children with Peutz-Jeghers Syndrome. European journal of pediatric surgery : official journal of Austrian Association of Pediatric Surgery [et al] = Zeitschrift fur Kinderchirurgie. 2019.

20. Ko BM. [Small Bowel Tumors and Polyposis: How to Approach and Manage?]. The Korean journal of gastroenterology = Taehan Sohwagi Hakhoe chi. 2018;72(6):277-80.

21. Kumar S, Arora P, Goswami P. Recurrent intestinal obstruction in a patient of Peutz-Jeghers syndrome. Journal of cancer research and therapeutics. 2019;15(1):252-4.

22. Latchford A, Cohen S, Auth M, Scaillon M, Viala J, Daniels R, Talbotec C, Attard T, Durno C, Hyer W. Management of Peutz-Jeghers Syndrome in Children and Adolescents: A Position Paper From the ESPGHAN Polyposis Working Group. Journal of pediatric gastroenterology and nutrition. 2019;68(3):44252.

23. Sureka S, Gupta G, Agarwal M, Mishra A, K Singh S, P Singh R, Sah SK, de Jesus A Pinto T, Dua K. Formulation, in-vitro and ex-vivo evaluation of tretinoin loaded cubosomal gel for the treatment of acne. Recent patents on drug delivery \& formulation. 2018;12(2):121-9.

24. Wadhwa R, Aggarwal T, Malyla V, Kumar N, Gupta G, Chellappan DK, Dureja H, Mehta M, Satija $\mathrm{S}$, Gulati M. Identification of biomarkers and genetic approaches toward chronic obstructive pulmonary disease. Journal of cellular physiology. 2019.

25. Lee MH, Kim ES, Choi MC, Heo JH, Jang JH, Jung SG, Park H, Joo WD, Lee C, Lee JH. Minimal deviation adenocarcinoma (adenoma malignum) of the uterine cervix: clinicopathological analysis of 17 cases. Obstetrics \& gynecology science. 2018;61(5):590-7.

26. Leung AKC, Lam JM, Leong KF, Sergi CM. Melanonychia striata: clarifying behind the Black Curtain. A review on clinical evaluation and management of the 21st century. International journal of dermatology. 2019;58(11):1239-45.

27. Li BR, Sun T, Li J, Zhang YS, Ning SB, Jin XW, Zhu M, Mao GP. Primary experience of small bowel polypectomy with balloon-assisted enteroscopy in young pediatric Peutz-Jeghers syndrome patients. European journal of pediatrics. 2019.

28. Li F, Mehta N, Liska D, Dionigi B, Kalady MF, Burke CA, Bhatt A. Combined endoscopic and surgical management of small-bowel polyposis in a patient with Peutz-Jeghers syndrome. Endoscopy. 2019.

29. Li M, Sun T, Jiang Y, Li J, Ning S, Zhou P. [Analysis of STK11 gene variants among 64 patients with Peutz-Jeghers syndrome]. Zhonghua yi xue yi chuan xue za zhi = Zhonghua yixue yichuanxue zazhi = Chinese journal of medical genetics. 2019;36(9):862-5.

30. Dua K, Gupta G, Chellapan DK, Bebawy M, Collet T. Nanoparticle-based therapies as a modality in treating wounds and preventing biofilm [Letter to the editor]. Panminerva Medica: A Journal on Internal Medicine. 2018;60(4):237-8. 
31. Gautam RK, Gupta G, Sharma S, Hatware K, Patil K, Sharma K, Goyal S, Chellappan DK, Dua K. Rosmarinic acid attenuates inflammation in experimentally induced arthritis in Wistar rats, using Freund's complete adjuvant. International journal of rheumatic diseases. 2019.

32. Gupta G, Chellappan D, Mishra A, Malipeddi H, Dua K. A clinical update on metformin and lung cancer in diabetic patients. Panminerva medica. 2018;60(2):70-5.

33. Li Z, Song M, Jiang H, Zhou Y. Peutz-Jeghers syndrome complicated with intussusception in late pregnancy. The Lancet Oncology. 2019;20(12):e729.

34. Lipsa A, Kowtal P, Sarin R. Novel germline STK11 variants and breast cancer phenotype identified in an Indian cohort of Peutz-Jeghers syndrome. Human molecular genetics. 2019;28(11):1885-93.

35. Marginean CO, Melit LE, Patraulea F, lunius S, Marginean MO. Early onset Peutz-Jeghers syndrome, the importance of appropriate diagnosis and follow-up: A case report. Medicine. 2019;98(27):e16381.

36. Matsubayashi H, Kiyozumi Y, Ishiwatari H, Uesaka K, Kikuyama M, Ono H. Surveillance of Individuals with a Family History of Pancreatic Cancer and Inherited Cancer Syndromes: A Strategy for Detecting Early Pancreatic Cancers. Diagnostics (Basel, Switzerland). 2019;9(4).

37. Samuel VP, Dahiya R, Singh Y, Gupta G, Sah SK, Gubbiyappa SK, Chellappan DK, Dua K. Metformin: A Salutary Candidate for Colorectal Cancer Treatment in Patients with Diabetes. Journal of Environmental Pathology, Toxicology and Oncology. 2019;38(2).

38. Singh Y, Gupta G, Sharma R, Matta Y, Mishra A, Pinto TdJA, Dua K. Embarking Effect of ACE2Angiotensin 1-7/Mas Receptor Axis in Benign Prostate Hyperplasia. Critical Reviews ${ }^{\mathrm{TM}}$ in Eukaryotic Gene Expression. 2018;28(2).

39. Tiwari J, Bajpai K, Gupta G, Sharma R, Verma RK, Dua K. Tetrahydrocannabinol: a drug of interest. Panminerva medica. 2018;60(4):228.

40. Mettang T, Streit M. [Dermal Clues to Systemic Diseases]. Deutsche medizinische Wochenschrift (1946). 2018;143(23):1690-9.

41. Milicevic T, Zaja I, Tesanovic D, Radman M. Laugier-Hunziker syndrome in endocrine clinical practice. Endocrinology, diabetes \& metabolism case reports. 2018;2018.

42. Mirkovic J, Dong F, Sholl LM, Garcia E, Lindeman N, MacConaill L, Crum CP, Nucci MR, McCluggage WG, Howitt BE. Targeted Genomic Profiling of Female Adnexal Tumors of Probable Wolffian Origin (FATWO). International journal of gynecological pathology : official journal of the International Society of Gynecological Pathologists. 2019;38(6):543-51.

43. Gupta G, Afzal M, David SR, Verma R, Candaswamy M, Anwar F. Anticonvulsant activity of Morus alba and its effect on brain gamma-aminobutyric acid level in rats. Pharmacognosy research. 2014;6(2):188.

44. Gupta G, Dua K. Rajendra Awasthi1, Satish Manchanda2, Poppy Das3, Vinodhini Velu3, Himaja Malipeddi3, Kavita Pabreja4, Terezinha DJA Pinto5. Engineering of Biomaterials for Drug Delivery Systems: Beyond Polyethylene Glycol. 2018:255.

45. Gupta G, Kazmi I, Afzal M, Rahman M, Saleem S, Ashraf MS, Khusroo MJ, Nazeer K, Ahmed S, Mujeeb M. Sedative, antiepileptic and antipsychotic effects of Viscum album L.(Loranthaceae) in mice and rats. Journal of ethnopharmacology. 2012;141(3):810-6.

46. Miyahara K, Tobe S, Shizuku T, Inamoto R, Katayama I. Colon cancer of Peutz-Jeghers syndrome with gallolyticus endocarditis. Clinical journal of gastroenterology. 2019.

47. Miyasako Y, Kuwai T, Imagawa H, Kohno H, Ishaq S. Underwater EMR with submucosal lift for a small intestinal polyp in a patient with Peutz-Jeghers syndrome. VideoGIE : an official video journal of the American Society for Gastrointestinal Endoscopy. 2018;3(4):119-20.

48. Mork M, Quesada PR, Bannon S, Montiel MF, Fleming JB, Lynch PM, Bhutani MS, Lee JH, McAllister F. Pancreatic Cancer Early Detection and Interception in an Atypical Case of Peutz-Jeghers Syndrome. Pancreas. 2019;48(4):e29-e30. 
49. Gupta G, Chellappan DK, Agarwal M, Ashwathanarayana M, Nammi S, Pabreja K, Dua K. Pharmacological evaluation of the recuperative effect of morusin against aluminium trichloride (AICl3)induced memory impairment in rats. Central Nervous System Agents in Medicinal Chemistry (Formerly Current Medicinal Chemistry-Central Nervous System Agents). 2017;17(3):196-200.

50. Hansbro PM, Dua K. Rajendra Awasthi, Anurag Kumar Singh, Gaurav Mishra, Anand Maurya, Dinesh Kumar Chellappan, Gaurav Gupta. Circular RNAs: Biogenesis and Functions. 2018;1087:1.

51. Kazmi I, Gupta G, Afzal M, Anwar F. Anticonvulsant and depressant-like activity of ursolic acid stearoyl glucoside isolated from Lantana camara L.(verbanaceae). Asian Pacific Journal of Tropical Disease. 2012;2:S453-S6.

52. Nassif M, Gawrieh B, Abdo A, Alshehabi Z, Ali W. Sporadic Peutz-Jeghers syndrome: a rare cause of intussusception in a toddler with no medical history. Oxford medical case reports. 2019;2019(6):omz051.

53. Nevozinskaya Z, Korsunskaya I, Sakaniya L, Perlamutrov Y, Sobolev V. Peutz-Jeghers syndrome in dermatology. Acta dermatovenerologica Alpina, Pannonica, et Adriatica. 2019;28(3):135-7.

54. Nobori Y, Amano T, Ochi M, Kumasaka T, Sunami E. Rectal cancer developing from an anastomotic site 18 years after resection due to intussusception caused by Peutz-Jeghers polyposis in a 31-year-old man: a case report. Surgical case reports. 2018;4(1):110.

55. Gupta G, Kazmi I, Afzal M, Upadhyay G, Singh R, Habtemariam S. Antidepressant-like activity of Embelin isolated from Embelia ribes. Phytopharmacology. 2013;4(1):87-95.

56. Gupta G, Singh R, David SR, Verma RK. Effect of Rosiglitazone, a PPAR- $\gamma$ Ligand on HaloperidolInduced Catalepsy. CNS neuroscience \& therapeutics. 2013;19(9):724.

57. Madhu A, Gupta G, Arali B, K Chellappan D, Dua K. Anti-psychotic activity of aqueous root extract of Hemidesmus indicus: a time bound study in rats. Recent patents on drug delivery \& formulation. 2017;11(1):36-41.

58. Ohmoto A, Yachida S, Morizane C. Genomic Features and Clinical Management of Patients with Hereditary Pancreatic Cancer Syndromes and Familial Pancreatic Cancer. International journal of molecular sciences. 2019;20(3).

59. Patel R, Hyer W. Practical management of polyposis syndromes. Frontline gastroenterology. 2019;10(4):379-87.

60. Pelit ES, Erol B, Zenginkinet T, Caskurlu T. Testis-sparing surgery of unilateral testicular large-cell calcifying Sertoli cell tumor: a sporadic case. Turkish journal of urology. 2018;44(4):370-2.

61. Pennazio M, Venezia L, Gambella A, Cortegoso Valdivia P. Underwater endoscopic mucosal resection of a large jejunal polyp by single-balloon enteroscopy in a patient with Peutz-Jeghers syndrome. Digestive and liver disease : official journal of the Italian Society of Gastroenterology and the Italian Association for the Study of the Liver. 2019;51(1):170-2.

62. Pinna R, Cocco F, Campus G, Conti G, Milia E, Sardella A, Cagetti MG. Genetic and developmental disorders of the oral mucosa: Epidemiology; molecular mechanisms; diagnostic criteria; management. Periodontology 2000. 2019;80(1):12-27.

63. Plataras C, Christianakis E, Fostira F, Bourikis G, Chorti M, Bourikas D, Fotopoulos N, Damalas K, Eirekat K. Asymptomatic Gastric Giant Polyp in a Boy with Peutz-Jeghers Syndrome Presented with Multiple Cafe Au Lait Traits. Case reports in surgery. 2018;2018:6895974.

64. Parambath A. Engineering of biomaterials for drug delivery systems: beyond polyethylene glycol. Woodhead Publishing; 2018.

65. Rahman M, Zaki Ahmad M, Kazmi I, Akhter S, Beg S, Gupta G, Afzal M, Saleem S, Ahmad I, Shaharyar A. Insight into the biomarkers as the novel anti-psoriatic drug discovery tool: a contemporary viewpoint. Current drug discovery technologies. 2012;9(1):48-62.

66. Plevova P. An Update on Inherited Colon Cancer and Gastrointestinal Polyposis. Klinicka onkologie : casopis Ceske a Slovenske onkologicke spolecnosti. 2019;32(Supplementum2):97-108. 
67. Plevova P, Gerzova H. Genetic Causes of Rare Pediatric Ovarian Tumors. Klinicka onkologie : casopis Ceske a Slovenske onkologicke spolecnosti. 2019;32(Supplementum2):79-91.

68. Poffenberger MC, Metcalfe-Roach A, Aguilar E, Chen J, Hsu BE, Wong AH, Johnson RM, Flynn B, Samborska B, Ma EH, Gravel SP, Tonelli L, Devorkin L, Kim P, Hall A, Izreig S, Loginicheva E, Beauchemin $\mathrm{N}$, Siegel PM, Artyomov MN, Lum JJ, Zogopoulos G, Blagih J, Jones RG. LKB1 deficiency in T cells promotes the development of gastrointestinal polyposis. Science (New York, NY). 2018;361(6400):40611.

69. Qiu Y, Xuan T, Yin M, Gao Z, Guo P, Chen X, Ye Y, Shen Z. Clinical characteristics and genetic analysis of gene mutations in a Chinese pedigree with Peutz-Jeghers syndrome. Clinical case reports. 2019;7(4):735-9.

70. Renes JS, Knijnenburg J, Chitoe-Ramawadhdoebe S, Gille JJP, de Bruin C, Barge-Schaapveld D. Possible hints and pitfalls in diagnosing Peutz-Jeghers syndrome. Journal of pediatric endocrinology \& metabolism : JPEM. 2018;31(12):1381-6.

71. Rajeshkumar S, Menon S, Kumar SV, Tambuwala MM, Bakshi HA, Mehta M, Satija S, Gupta G, Chellappan DK, Lakshmi T. Antibacterial and antioxidant potential of biosynthesized copper nanoparticles mediated through Cissus arnotiana plant extract. Journal of Photochemistry and Photobiology B: Biology. 2019:111531.

72. Samvedna S, Jindal S, Mishra G, Madan JR, Gupta G, Awasthi R, Pinto TDJA, Dua K, Kulkarni GT. Formulation and characterization of oral rapid disintegrating tablets of levocetirizine. Polymers in Medicine. 2018;48(1):31-40.

73. Sharma S, Pathak S, Gupta G, Sharma SK, Singh L, Sharma RK, Mishra A, Dua K. Pharmacological evaluation of aqueous extract of syzigium cumini for its antihyperglycemic and antidyslipidemic properties in diabetic rats fed a high cholesterol diet-Role of PPARY and PPAR $\alpha$. Biomedicine \& Pharmacotherapy. 2017;89:447-53.

74. Rodriguez Lagos FA, Sorli Guerola JV, Romero Martinez IM, Codoner Franch P. Register and clinical follow-up of patients with Peutz-Jeghers syndrome in Valencia. Revista de gastroenterologia de Mexico. 2019.

75. Sado T, Nakayama Y, Kato S, Homma H, Kusakari M, Hidaka N, Gomi S, Takamizawa S, Kosho T, Saito $S$, Sugano K. Extremely young case of small bowel intussusception due to Peutz-Jeghers syndrome with nonsense mutation of STK11. Clinical journal of gastroenterology. 2019;12(5):429-33.

76. Sanchez-Mete L, Stigliano V. Update on small bowel surveillance in hereditary colorectal cancer syndromes. Tumori. 2019;105(1):12-21.

77. Sanese P, Forte G, Disciglio V, Grossi V, Simone C. FOXO3 on the Road to Longevity: Lessons From SNPs and Chromatin Hubs. Computational and structural biotechnology journal. 2019;17:737-45. 78. Satiya J, Girotra M. A Rare Double Primary Tumor of the Pancreas and the Esophagus. Cureus. 2019;11(6):e4955.

79. Sengupta S, Bose S. Peutz-Jeghers Syndrome. The New England journal of medicine. 2019;380(5):472.

80. Shah J, Sunkara T, Xiao P, Gaduputi V, Reddy M, Razia S. Peutz-Jeghers Syndrome Presenting as Colonic Intussusception: A Rare Entity. Gastroenterology research. 2018;11(2):150-3. 